\title{
Annonaceae das restingas do estado do Rio de Janeiro, Brasil
}

\author{
Adriana Quintella Lobão ${ }^{1}$, Dorothy Sue Dunn de Araujo ${ }^{2} \&$ Bruno Coutinho Kurtz ${ }^{1}$
}

\section{Resumo}

(Annonaceae das restingas do estado do Rio de Janeiro, Brasil.) A família Annonaceae está representada nas restingas do estado do Rio de Janeiro por nove espécies: Anaxagorea dolichocarpa Sprague \& Sandwith, Annona acutiflora Mart., A. glabra L., A. montana Macfad., Duguetia sessilis (Vell.) Maas, Guatteria nigrescens Mart., Oxandra nitida R.E.Fr., Xylopia ochrantha Mart. e X. sericea A.St.-Hil. Apresentam-se chave de identificação das espécies, breves descrições, ilustrações e comentários sobre fenologia, distribuição geográfica, habitats e usos.

Palavras-chave: Annonaceae, flora, taxonomia.

\section{Abstract}

(Annonaceae of the restingas of Rio de Janeiro State, Brazil) The family Annonaceae is represented in the restingas (sandy coastal plains) of Rio de Janeiro State by nine species: Anaxagorea dolichocarpa Sprague \& Sandwith, Annona acutiflora Mart., A. glabra L., A. montana Macfad., Duguetia sessilis (Vell.) Maas, Guatteria nigrescens Mart., Oxandra nitida R.E.Fr., Xylopia ochrantha Mart. and X. sericea A.St.-Hil. A species key, short descriptions, illustrations and comments on the phenology, geographic distribution, habitats and uses are included.

Key-words: Annonaceae, flora, taxonomy.

\section{INTRODUÇão}

O termo restinga pode ser usado no sentido geomorfológico, significando diversos tipos de depósitos arenosos litorâneos de origem marinha, ou no sentido botânico, designando o conjunto de comunidades vegetais fisionomicamente distintas, sob influência marinha e fluvio-marinha (Araujo 1992).

As restingas do estado do Rio de Janeiro ocupam uma área de $1.200 \mathrm{~km}^{2}$, ou seja, cerca de 2,8\% de seu território (Araujo \& Maciel 1998). São encontradas 10 comunidades vegetais nessas planícies arenosas costeiras, variando de herbáceas até arbóreas (Araujo et al. 1998). Essas comunidades ocupam habitats marginais à mata atlântica e são extremamente frágeis devido a sua dependência em reduzido número de espécies focais (Scarano 2002).

Annonaceae constitui a principal família do clado Magnoliales (APG 2003) e é uma das maiores entre as Angiospermas, com cerca de 135 gêneros e 2.500 espécies (Chatrou et al. 2004). A família possui distribuição pantropical, sendo que no neotrópico está representada por aproximadamente 40 gêneros e 900 espécies (Chatrou et al. 2004) e no Brasil por 26 gêneros (sete endêmicos) com cerca de 260 espécies (Maas et al. 2002). Apresenta considerável riqueza de espécies principalmente na região amazônica e na floresta atlântica (s.l.).

Annonaceae é conhecida principalmente por seus frutos comestíveis, tais como a fruta do conde ou ata (Annona squamosa L.) e a graviola (A. muricata L.). Além disso, algumas espécies fornecem madeira própria para carpintaria e raízes utilizáveis como cortiça ( $A$. glabra L., A. crassiflora Mart.); outras são consideradas medicinais (A. spinescens Mart., A. foetida Mart.) e ornamentais (A. cacans Warm. e Xylopia sericea A.St.-Hil.) (Corrêa 1984).

São arbustos, arvoretas ou árvores. Tricomas simples, escamiformes ou estrelados. Folhas alternas, simples, dísticas. Flor 1 ou em inflorescência, axilar, extra-axilar, opositifolia,

Artigo recebido em 03/2005. Aceito para publicação em 07/2005.

${ }^{1}$ Instituto de Pesquisas Jardim Botânico do Rio de Janeiro, rua Pacheco Leão 915, 22460-030, Rio de Janeiro, RJ, Brasil, alobao@hotmail.com

${ }^{2}$ Laboratório de Ecologia Vegetal, Instituto de Biologia, Universidade Federal do Rio de Janeiro, Caixa Postal 68020, Ilha do Fundão, CEP 21941-590, Rio de Janeiro, RJ, Brasil. 
caulinar ou em ramo flageliforme; sépalas três; pétalas seis, em dois ciclos, subiguais a bastante diferentes entre si; estames poucos a numerosos, conectivo dilatado em forma de disco; carpelos poucos a numerosos, livres ou soldados na base. Fruto apocárpico, pseudosincárpico ou sincárpico; carpídios deiscentes ou indeiscentes. Sementes com endosperma ruminado e embrião diminuto.

Este trabalho tem como finalidade ampliar o conhecimento sobre as espécies de Annonaceae ocorrentes nas restingas do estado do Rio de Janeiro.

\section{Material e Métodos}

As descrições, ilustrações e informações sobre floração e frutificação das espécies foram baseadas nos materiais das restingas do estado do Rio de Janeiro depositados principalmente no herbário RB. Quando necessário foi utilizado material adicional. Informações relacionadas à distribuição geográfica e usos foram obtidas da literatura. Os materiais analisados estão organizados em ordem alfabética de municípios e, dentro desses, em ordem cronológica. A terminologia morfológica foi baseada em Radford et al. (1974).

Apresenta-se chave de identificação das espécies, breves descrições, ilustrações, e comentários sobre fenologia, distribuição geográfica, habitat e usos das espécies.

\section{Resultados e Discussão}

Nas restingas do Rio de Janeiro, Annonaceae está representada por seis gêneros e nove espécies: Anaxagorea dolichocarpa, Annona acutiflora, A. glabra, A. montana, Duguetia sessilis, Guatteria nigrescens, Oxandra nitida, Xylopia ochrantha e X. sericea.

Das espécies aqui tratadas, somente Annona glabra possui ampla distribuição nas planícies arenosas do sul e sudeste brasileiro. As outras espécies, com exceção de Duguetia sessilis, que é endêmica ao estado do Rio de Janeiro, e Annona montana, que é citada aqui pela primeira vez em restinga, ocorrem nas restingas do Espírito Santo e/ou Bahia.

\section{Chave para identificação das espécies}

1. Fruto apocárpico ou pseudo-sincárpico. Flor axilar, caulinar ou em ramo flageliforme.

2. Carpídios deiscentes. Estaminódios presentes.

3. Botão ovóide. Anteras não septadas transversalmente. Carpídios claviformes 1. Anaxagorea dolichocarpa

3'. Botão estreitamente piramidal. Anteras septadas transversalmente. Carpídios elipsóides.

4. Flores caulinares. Lâminas foliares 6-10 x 2,5-4 cm, elípticas, glabras em ambas as faces 8. Xylopia ochrantha

4'. Flores axilares. Lâminas foliares 7-10,5 x 1-2 cm, estreitamente elípticas, glabras na face adaxial, densamente cobertas por tricomas adpressos na face abaxial .... 9. Xylopia sericea

2'. Carpídios indeiscentes. Estaminódios ausentes.

5. Fruto apocárpico. Flor 1 ou em inflorescência, axilar.

6. Flor 1. Carpídios com estipes ca. 5-10 mm compr.

6. Guatteria nigrescens

6'. Flor em inflorescência. Carpídios sésseis

7. Oxandra nitida

5'. Fruto pseudo-sincárpico. Flores em inflorescência, em ramo flageliforme partindo da base do tronco paralelamente ao solo 5. Duguetia sessilis

1'. Fruto sincárpico. Flor extra-axilar, opositifolia ou caulinar.

7. Botão falciforme

2. Annona acutiflora

7'. Botão ovóide ou triangular-ovóide.

8. Botão 15-20 x 20 mm, ovóide. Lâminas foliares subcoriáceas; domácias ausentes

8'. Botão 20 × 25 mm, triangular-ovóide. Lâminas foliares cartáceas; domácias presentes 
Anaxagorea A.St.-Hil.

Árvores, arvoretas ou arbustos. Tricomas simples ou estrelados, microscópicos. Flor 1 ou em inflorescência, axilar ou raramente terminal, monoclina; sépalas três, raramente 2 , livres ou conatas na base, valvares ou imbricadas; pétalas seis, raramente 3 , liv res, valvares, as internas menores; estames numerosos; anteras não septadas transversalmente, estaminódios presentes; conectivo dilatado, plano; carpelos poucos a numerosos, óvulos dois, sub-basais. Fruto apocárpico, carpídios claviformes, explosivamente deiscentes; sementes duas, sem arilo, lustrosas.

Anaxagorea possui cerca de 26 espécies. Ocorre no México, América Central, América do Sul e Ásia tropical (Maas \& Westra 1984-1985).

\section{Anaxagorea dolichocarpa Sprague \&} Sandwith, Bull. Misc. Inform. 1930: 475. 1930.

Figura: Steyermark et al. 1995; Pontes et al. 2004.

Arbustos ou arvoretas, ca. $7 \mathrm{~m}$ alt. Tricomas simples ou estrelados. Pecíolo 5-12 mm compr., marrom. Lâminas foliares 16-33 x 7-10 cm, subcoriáceas, elípticas, verdes discolores, glabras em ambas as faces; base aguda a obtusa; ápice agudo; nervura primária impressa na face adaxial, proeminente na abaxial. Flor 1, axilar, creme ou amarela; botão 10-23 x 8-20 mm, ovóide; pedicelo ca. $10 \mathrm{~mm}$ compr.; brácteas depresso-ovadas; sépalas ca. 10 x 6-8 mm, livres, glabras; pétalas do ciclo externo $14-15 \times 7-8 \mathrm{~mm}$, cobertas por tricomas na face abaxial, do interno 11-13 x 5-6 mm, menores que as do ciclo externo; estames 5-6 $\mathrm{mm}$ compr.; carpelos ca. $5 \mathrm{~mm}$ compr., numerosos. Fruto apocárpico, carpídios 15-25 x 10-13 mm, estipes 1,5-2 cm compr., verdes, glabros.

Material analisado: Rio de Janeiro, Restinga da Marambaia, Praia da Armação,
7.IV.2000, st., L. F. T. Menezes 659 (RBR); ib., 8.IV.2000, st., L. F. T. Menezes 594 (RBR).

Material adicional analisado: RIO DE JANEIRO: Parati, São Roque, caminho para Cunha, 13.XII.1988, fl., V. L. G. Klein et al. 582 (RB). Rio de Janeiro, Mata do Pai Ricardo, perto da Sede do Horto Florestal, 17.VI.1927, fr., Pessoal do Horto Florestal s.n. (RB 76972); Vista Chinesa, 18.IX.1946, fl., P. Occhioni 713 (HBR, MO, NY, RB); Horto Florestal do Jardim Botânico do Rio de Janeiro, Grotão, Pedra d'Água, elev. 150-200 m, 1.VIII.1977, fr., G. Martinelli 2826 (RB). Anaxagorea dolichocarpa possui ampla distribuição geográfica, da Costa Rica (Península do Osa) até a Bolívia e, no Brasil, no Amapá, Amazonas, Acre, Rondônia, Goiás, Maranhão, Paraíba, Pernambuco, Bahia e Rio de Janeiro, habitando florestas úmidas (Maas \& Westra 1984-1985, Pontes et al. 2004). Até o momento, só foi coletada (estéril) na restinga da Marambaia, na floresta seca e na floresta periodicamente inundada.

\section{Annona L.}

Árvores, arvoretas ou arbustos. Tricomas simples ou estrelados. Domácias ausentes ou presentes. Flor 1 ou em inflorescência, terminal, opositifolia ou infra-axilar, monoclina, raramente diclina; sépalas três, livres ou conatas; pétalas seis, raramente três, livres ou conatas na base, as externas valvares, as internas valvares ou imbricadas; estames numerosos, conectivo dilatado em forma de disco, raramente apiculado ou semi-orbicular; anteras não septadas transversalmente, estaminódios ausentes; carpelos numerosos, óvulo um, basal. Fruto sincárpico, carnoso, indeiscente; sementes muitas, sem arilo.

Annona possui cerca de 110 espécies neotropicais e quatro africanas (Chatrou et al. 2004). Algumas são cultivadas pelos frutos comestíveis (Corrêa 1984). 
2. Annona acutiflora Mart. in Mart., Fl. bras. 13(1): 10. 1841.

Nomes populares: pau de guiné, raiz de guiné (Corrêa 1984), guiné (Fonseca 1998).

Figura $1 \mathrm{a}-\mathrm{b}$.

Arvoretas, 1,5-4m alt. Tricomas simples. Gemas cobertas por tricomas ferrugíneos. Pecíolo 5-7 mm compr., marrom. Lâminas foliares 7,5-13(-19) x 3-5(-6) cm, cartáceas, estreitamente elípticas, verdes discolores, glabras em ambas as faces; base aguda; ápice acuminado, acúmem até $1,5 \mathrm{~cm}$ compr.; domácias ausentes; nervura primária impressa nabase e proeminente no ápice da face adaxial, proeminente na abaxial. Flor 1, extra-axilar, monoclina; botão 6-20 mm compr., falciforme; pedicelo 5-10 mm compr.; brácteas muitas, cobertas por tricomas ferrugíneos; sépalas e pétalas cobertas por tricomas ferrugíneos na face abaxial; sépalas ca. 5 × $3 \mathrm{~mm}$, livres; pétalas do ciclo externo 10-20 x 5-6 mm na base, ca. $2 \mathrm{~mm}$ no ápice, do interno ca. 4,5 x $3,5 \mathrm{~mm}$, menores que do ciclo externo, conatas na base, tubo da corola ca. $4 \mathrm{~mm}$ compr.; estames ca. $2 \mathrm{~mm}$ compr.; carpelos ca. 1,5 $\mathrm{mm}$ compr., seríceos na base. Fruto sincárpico, obovóide, 2-4(-8) x 2-3(-6) cm, imaturo verde e maduro glauco-esverdeado a verde.

Material analisado: Armação dos Búzios: Praia Gorda, 6.VII.1999, fl., A. Q. Lobão et al. 434 (RB);Praia de Manguinhos, 12.XI. 1999, fl., D. Oliveira \& J. C. Gomes 294 (RB). Cabo Frio: Campos Novos, estrada de Campos, 30.XII.1964, fl., A. P. Duarte 8652 (RB); Tamoios, estrada para a fazenda da Pedra, próximo ao rio São João, 10.XI.2000, fl. e fr., C. Farney \& J. C. Gomes 4314 (RB). Rio das Ostras: 6.V.1971, fr., L. Krieger 10443 (RB). Rio de Janeiro: Restinga da Lagoinha da Gávea, 2.X.1948, fr., O. Machado s.n. (RB 79125); Restinga de Jacarepaguá, canal das Taxas, 14.XII.1967, fr., A. S. Moreira \& P. Carauta 509 (RB); ib., estrada do Autódromo, 6.I.1972, fr., D. Araujo 42 (RB); Restinga de Grumari, 14. VIII. 1968, fr., D. Sucre 3504 (RB); estrada Barra-Jacarepaguá (Av. Alvorada, atual Av. Ayrton Senna), 16.XII. 1971, fr., D. Sucre 8106 (RB); Barra da Tijuca, km $15 \mathrm{~W}$ da Barra, na rodovia RioSantos, 232'S - 43²6'W, 26.II.1988, fl., W. W. Thomas s.n. (RB 319105). Saquarema: Reserva Ecológica Estadual de Jacarepiá, 29.X.1991, fl., C. Farney et al. 2779 (RB); ib., 17.XII.1996, fl., C. Farney 3559 (RB).

Annona acutiflora se caracteriza pelo botão falciforme distinto das demais espécies do gênero (Fig. 1a). Apresenta uso religioso, na forma de banho contra mau-olhado e/ou feitiçaria. O fruto é comestível e apreciado pelo sabor azedo, parecido com pinha (Fonseca 1998) (Fig. 1b). Ocorre na Bahia, Espírito Santo e Rio de Janeiro. No Rio de Janeiro é encontrada na floresta pluvial atlântica de baixada e restinga (Kurtz 2001; Maas et al. 2002; Fries 1931). Nessa, ocorre nas formações arbustivas fechadas e abertas (incluindo a formação de Clusia do Parque Nacional da Restinga de Jurubatiba) enas florestas sobre cordão (mata seca) e entre cordões arenosos (florestas permanente e periodicamente inundadas). Nas restingas do Rio de Janeiro, foi coletada em flor e fruto durante todo o ano.

3. Annona glabra L., Sp. pl. 537. 1753. Nomes populares: Araticum do brejo, araticum cortiça, araticum da praia, araticum de jangada, entre outros (Corrêa 1984).

Figura $1 \mathrm{c}-\mathrm{d}$.

Arbustos ou arvoretas, ca. $3 \mathrm{~m}$ alt. Tricomas simples. Pecíolo 1,2-2 cm compr., marrom. Lâminas foliares 6-12 x 3,5-6 cm, subcoriáceas, elípticas, verdes discolores, glabras em ambas as faces; base truncada; ápice agudo a curto acuminado, acúmem até $1 \mathrm{~mm}$ compr.; domácias ausentes; nervura primária impressa na base e proeminente no ápice da face adaxial, proeminente na abaxial. Flor 1, extra-axilar, monoclina; botão 15-20 x $20 \mathrm{~mm}$, ovóide; pedicelo ca. $1 \mathrm{~cm}$ compr.; brácteas depresso-ovadas; sépalas e pétalas glabras; sépalas ca. 3 x $3 \mathrm{~mm}$, livres; pétalas do ciclo externo ca. $15 \times 15 \mathrm{~mm}$, do interno ca. $14 \times 8 \mathrm{~mm}$, menores que as do ciclo externo; estames ca. $2 \mathrm{~mm}$ compr.; carpelos ca. $1 \mathrm{~mm}$ compr., seríceos na base. Fruto sincárpico, obovóide, 6-8,5 x 4,5-8 cm, verde. 

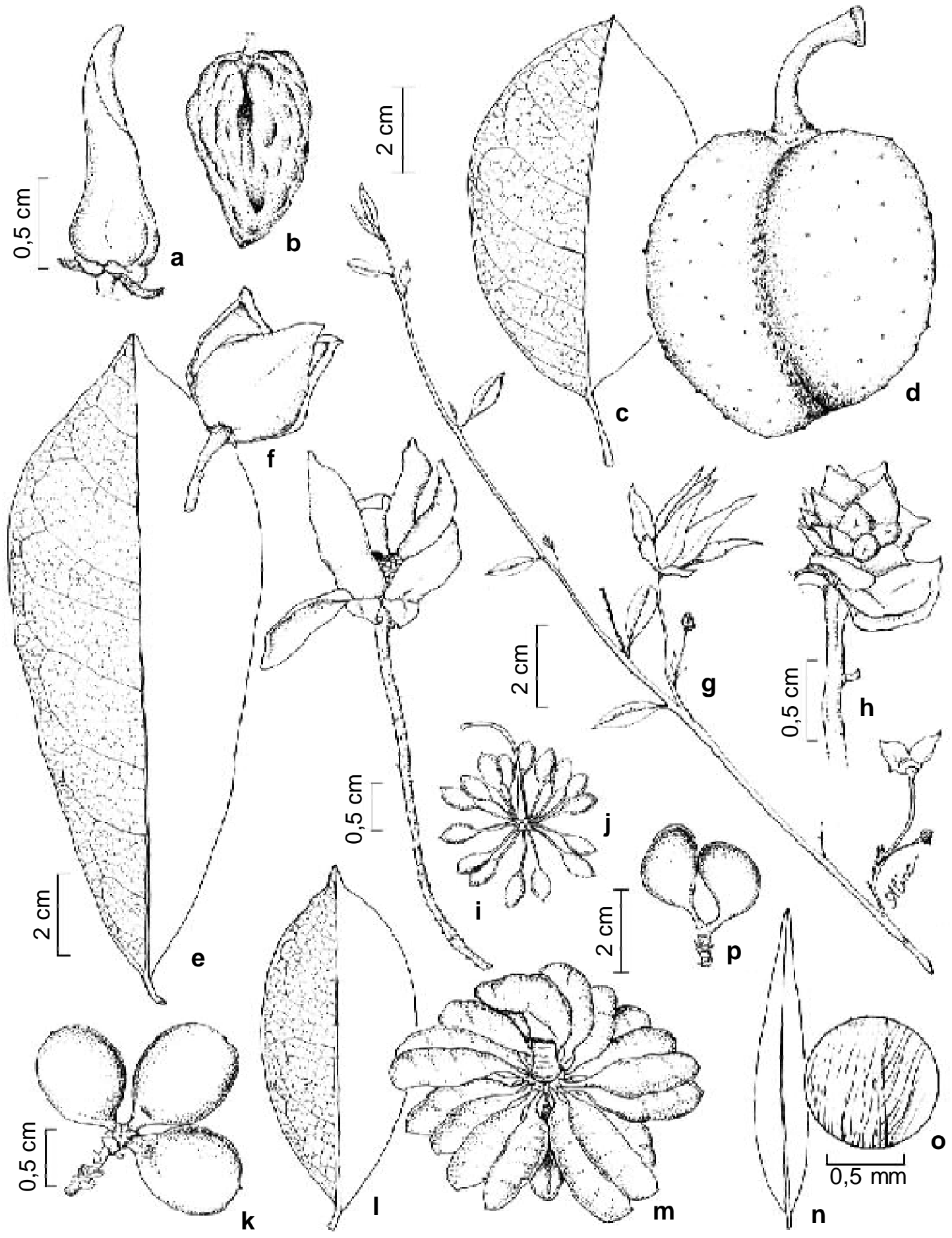

Figura 1 - a-b: Annona acutiflora. a - botão; b - fruto. c-d: Annona glabra. c - folha; d - fruto. e-f: Annona montana. e folha; f - flor. g-h: Duguetia sessilis. $\mathrm{g}$ - inflorescência em ramo flageliforme; h - fruto imaturo. i-j: Guatteria nigrescens. i - flor; j- fruto. k: Oxandra nitida. fruto. l-m: Xylopia ochrantha. 1 - folha; $\mathrm{m}$ - fruto. n-p: Xylopia sericea. n - folha; o detalhe do indumento da lâmina foliar na face abaxial; p - fruto. (a-b: Lobão 434; c-d: Lobão 300b; e-f: Kurtz 306; g: Farney 2459; h: Kurtz 307; i: Kurtz 294; j: Sucre 3184; k: Maas 8840; 1-m: Farney 3402; n-p: Guedes 946) 
Material analisado: Angra dos Reis: estrada Angra dos Reis-Parati, elev. 10 m, 30.III.1974, fr., D. Sucre 10685 (RB). Armação dos Búzios: Praia de Tucuns, 16.II.2000, fr., D. Fernandes \& A. Oliveira 436 (RB). Mangaratiba: estrada antiga para Muriqui, 22.IX. 1975, fr., D. Araujo \& A. L. Peixoto 821 (RB). Saquarema: Jaconé, 30. VI.1998, fl. e fr., A. Q. Lobão et al. $300 b$ (RB). Rio de Janeiro: Lagoa Itapemirim, 9.XII.1915, fl., A. Frazão 33 (RB); Jacarepaguá, 6.III.1970, fr., D. Sucre \& S. P. Santos 6462 (RB).

Annona glabra caracteriza-se pelas folhas subcoriáceas e glabras com pecíolo longo variando de 1,2 a $2 \mathrm{~cm}$ de comprimento (Fig. 1c). Fornece madeira própria para carpintaria, caixotaria, ripas, mastros e remos de pequenas embarcações. As raízes são utilizadas como cortiça (Fonseca-Kruel \& Peixoto 2004). As folhas são anti-helmínticas e anti-reumáticas. Os frutos, embora considerados venenosos, são provavelmente comestíveis e utilizados como maturativos e anti-helmínticos (Corrêa 1984) (Fig. 1d). Segundo Corrêa (1984), a espécie foi há muitos anos levada da América para a África, onde se tornou subespontânea em algumas regiões. Espécie de ampla distribuição geográfica, ocorrendo nos Estados Unidos (Flórida), México, América Central, Antilhas, Colômbia, Venezuela, Guianas, Equad or e Brasil (Pernambuco, Bahia, Espírito Santo, Minas Gerais, Rio de Janeiro, São Paulo, Paraná e Santa Catarina). Ocorre ainda na costa ocidental da África, no Senegal, Gâmbia, Libéria, Costa do Marfim, Nigéria, Camarões e Gabão (Fries 1931; MelloSilva 1992). Segundo Mello-Silva (1992), habita zonas paludosas como mangues e restingas. Nas restingas do Rio de Janeiro, é encontrada em florestas permanentemente inundadas, em brejos e nas margens das lagoas. Nessas restingas foi coletada em flor em junho, setembro, novembro e dezembro e em fruto de janeiro a março, junho e dezembro.
4. Annona montana Macfad., Fl. Jamaica 1: 7. 1837.

Figura 1 e-f.

Arvoreta, ca. $7 \mathrm{~m}$ alt. Tricomas simples. Pecíolo 5-8 mm compr., negro. Lâminas foliares $10-18 \times 3,5-5,3 \mathrm{~cm}$, cartáceas, obovadas, verdes discolores, glabras em ambas as faces; base levemente decurrente; ápice acuminado, acúmem ca. $5 \mathrm{~mm}$ compr.; domácias presentes; nervura primária impressa na base e proeminente no ápice da face adaxial, proeminente na abaxial. Flor 1, opositifolia ou caulinar, monoclina; botão ca. $20 \times 25 \mathrm{~mm}$, triangular-ovóide; pedicelo 1,5-2 cm compr.; brácteas escamiformes; sépalas ca. 5 x $5 \mathrm{~mm}$, livres, esparsamente tomentosas na face abaxial; pétalas do ciclo externo ca. 23 x 18 $\mathrm{mm}$, tomentosas na face abaxial, do interno ca. 15 x $6 \mathrm{~mm}$, menores que as do ciclo externo; estames ca. $5 \mathrm{~mm}$ compr.; carpelos ca. $5 \mathrm{~mm}$ compr., seríceos na base. Frutos não vistos.

Material analisado: Carapebus: Entorno do Parque Nacional da Restinga de Jurubatiba, 21.XI.2002, fl., B. Kurtz et al. 306 (RB).

Annona montana caracteriza-se pelas folhas obovadas, que atingem cerca de $18 \mathrm{x}$ $5 \mathrm{~cm}$ (Fig. 1e), bastante parecidas com as de A. muricata (graviola), assim como o sabor do fruto que também é comestível. Das espécies de Annona das restingas do Rio de Janeiro, é a única que apresenta domácias na lâmina foliar. Ocorre também na Bahia, Goiás, Minas Gerais e São Paulo (Maas et al. 2002), além de ser amplamente distribuída pela América Central e do Sul, da Colômbia até a Bolívia (www.mobot.org - 4/7/2005). Espécie rara nas restingas do Rio de Janeiro, sendo encontrada até o momento no município de Carapebus, no entorno do Parque Nacional da Restinga de Jurubatiba, na borda de mata de cordão arenoso antropizada. Floresce em agosto. 
Duguetia A.St.-Hil.

Árvores ou arbustos. Tricomas escamiformes e/ou estrelados. Flor 1 ou em inflorescência, monoclina; sépalas três, livres ou conatas na base; pétalas seis, livres, imbricadas ou, às vezes, valvares; estames numerosos; anteras não septadas transversalmente, estaminódios ausentes; carpelos numerosos; óvulo um, basal. Fruto sincárpico ou pseudosincárpico, carnoso, indeiscente, anel basal presente formado por carpídios estéreis; sementes muitas, sem arilo ou arilo rudimentar.

Duguetia possui cerca de 93 espécies distribuídas na América do Sul e oeste da África (Maas \& Westra 2003).

5. Duguetia sessilis (Vell.) Maas, Candollea 49: 424. 1994. Maas et al., Flora Neotropica 88: 196. 2003.

Nome popular: Arco-de-pipa-da-restinga (Fonseca 1998).

Figura $1 \mathrm{~g}$-h.

Arvoretas ou árvores, 3-8 m alt. Tricomas escamiformes, escamas estreladas. Pecíolo 3-5 mm compr., atrofusco. Lâminas foliares 8-13 x 3-5 cm, cartáceas, elípticas, verdes discolores, cobertas por tricomas na face abaxial; base aguda a levemente decurrente; ápice agudo a acuminado, acúmem 1-2 cm compr.; nervura primária impressa na face adaxial, proeminente na abaxial. Flores em inflorescência, em ramo flageliforme partindo da base do tronco paralelamente ao solo, rosas a vermelhas; botão 7-10 x 6-8 mm, ovóide-triangular; pedicelo 2-3 cm compr.; brácteas muitas; sépalas e pétalas cobertas por tricomas; sépalas 6-11 x 5-8 mm; pétalas do ciclo externo $13-30$ x 5-8 mm, lineares, do interno 15-29 x 6-7 mm.; estames ca. $1 \mathrm{~mm}$ compr.; carpelos ca. $5 \mathrm{~mm}$ compr. Fruto pseudo-sincárpico, largamente elíptico, ca. 15 x $20 \mathrm{~mm}$.; sementes sem arilo.

Material analisado: Carapebus: Entorno do Parque Nacional da Restinga de Jurubatiba, 21.XI.2002, fl. e fr., B. Kurtz 307 (RB). Rio de Janeiro: Fortaleza de São João, 1916, fr., $A$. Frazão s.n. (RB 7146); Jacarepaguá, Represa do Cigano, III.1917, fr., J. G. Kuhlman s.n. (RB 8144). Saquarema: Reserva Ecológica Estadual de Jacarepiá, restinga de Ipitangas, próximo ao loteamento Vilatur, 22.XI.1986, fl., C. Farney \& J. C. Gomes 1272 (RB); ib., 8.XII.1986, fl. e fr., C. Farney \& J. C. Gomes 1287 (RB); ib., 25.XI.1988, fr., C. Farney et al. 2194 (RB); ib., 15.XI.1990, fr., C. Farney 2459 (RB); ib., 23.IV.1991, st., C. Farney 3196 (RB); ib., elev. 10-15m, 22 $55^{\circ} \mathrm{S}$ $42^{\circ} 26^{\prime}$ W, 22.II.1999, fl. e fr., J. P. Maas et al. 8838 (RB); restinga de Itaúna, 8.V.1985, fl., C. Farney et al. 714 (RB); restinga de Massambaba, 12.IX.1986, fl., C. Farney \& J. C. Gomes 1180 (RB).

Duguetia sessilis é caracterizada pela flagelifloria, ou seja, as flores são produzidas em longos ramos, originados da base do tronco, que crescem paralelamente ao solo, podendo atingir alguns metros de comprimento (Maas et al. 1993) (Fig. 1g). A madeira é utilizada para construção, geralmente como suporte do telhado das casas (Fonseca 1998). Espécie endêmica do estado do Rio de Janeiro, ocorrendo na floresta pluvial atlântica de baixada e restinga (Maas et al. 1993). Nessa, ocorre em mata sobre cordão (incluindo a transição para mata periodicamente inundada). Bastante comum. Nas restingas do Rio de Janeiro, foi coletada em flor em fevereiro, março, maio e de setembro a dezembro e em fruto em fevereiro, setembro, novembro e dezembro.

\section{Guatteria Ruiz \& Pav.}

Árvores, arvoretas ou arbustos. Tricomas simples. Flor em geral 1 ou em inflorescência, axilares, monoclinas; pedicelo articulado acima da base, brácteas abaixo da articulação; sépalas três, livres ou conatas no botão; pétalas seis, livres, imbricadas; estames numerosos, conectivo dilatado no ápice, em forma de disco truncado, às vezes umbonado, anteras não septadas transversalmente, estaminódios ausentes; carpelos numerosos, óvulo um, basal. Fruto apocárpico, carpídios em geral estipitados, indeiscentes; semente uma, sem arilo. 
Guatteria é o maior gênero da família, com cerca de 265 espécies (Chatrou et al. 2004), e o que apresenta os maiores problemas taxonômicos. É neotropical, ocorrendo da América Central ao sul do Brasil (Maas et al. 1994).

6. Guatteria nigrescens Mart. in Mart., Fl. bras. 13(1): 31. 1841.

Nome popular: Pindaiba.

Figura 1 i-j.

Arvoreta. Ramos jovens e adultos esparsamente cobertos por tricomas. Pecíolo 5-8 mm compr. Lâminas foliares 10-17 x 2,5-4 cm, cartáceas, estreitamente elípticas a elípticas, verdes discolores, glabras na face adaxial, esparsamente cobertas por tricomas na abaxial; base obtusa; ápice acuminado, acúmem ca. $15 \mathrm{~mm}$ compr.; nervura primária impressa na face adaxial, proeminente na abaxial. Flor 1, axilar; botão triangular-ovóide, sépalas livres no botão; pedicelo 3,5-6 cm compr.; brácteas cedo caducas; sépalas 7-10 x 5-6 mm, triangulares, valvares, glabras na base e vilosas no ápice da face abaxial, vilosas na adaxial; pétalas ovais, ápice agudo, as do ciclo externo $12-15 \times 5-7 \mathrm{~mm}$, as do interno 16-20 x 5-8 mm, sub-iguais, verde-claras a amareladas, quando maduras levemente avermelhadas e vilosas na face adaxial, glabras na base da face adaxial de ambos os ciclos; estames ca. $2 \mathrm{~mm}$ compr.; carpelos ca. $2 \mathrm{~mm}$ compr. Fruto apocárpico, carpídios 16-26, 810 x 5-6 mm, elipsóides, estipes $1-1,5 \mathrm{~cm}$ compr., vermelho-purpúreos, glabros.

Material analisado: Angra dos Reis: Ilha Grande, Reserva Biológica Estadual da Praia do Sul, Praia do Sul, $23^{\circ} 10^{\prime} \mathrm{S} 44^{\circ} 17^{\prime} \mathrm{W}$, 19.XII.1984, fl. e fr., D. Araujo 5490 (GUA, U); ib., na Baixada do Sul, 12.III.1986, fl., D. Araujo et al. 7293 (GUA); ib., 21.IV.1999, fr., A. Q. Lobão et al. 444 (SPF). Carapebus: Parque Nacional da Restinga de Jurubatiba, 13-17.VIII.2001, fl., B. Kurtz et al. 294 (RB).

Guatteria nigrescens caracteriza-se pelas lâminas foliares com ápice acuminado com acúmem com cerca de $15 \mathrm{~mm}$ compr. e pedicelo longo variando de 3,5-6 cm compr. (Fig. 1i). Assemelha-se a G. candolleana. Ambas possuem, em geral, folhas esparsamente cobertas por tricomas, pedicelo de 3,5$6 \mathrm{~cm}$ compr., sépalas livres no botão e pétalas com ápice agudo. Entretanto, G. nigrescens possui nervuras secundárias fortemente impressas na face adaxial e estipes de 15-25 mm compr. Por outro lado, G. candolleana possui lâmina foliar menor, nervuras secundárias levemente impressas na face adaxial e estipes de 8-17 mm compr. As duas espécies variam muito morfologicamente. Isto, aliado às suas semelhanças, pode ser indício da existência de um complexo de espécies.

Guatteria nigrescens distribui-se na mata secundária de terras baixas e na floresta submontana, na Zona da Mata de Minas Gerais, chegando a Ouro Preto, e na região costeira de São Paulo e Rio de Janeiro, onde chega a Santa Maria Madalena. É bastante comum ao longo do litoral norte de São Paulo e sul do Rio de Janeiro. Está frequientemente associada a cursos de rios ou locais alagados (Lobão 2003). No Parque Nacional da Restinga de Jurubatiba, norte fluminense, ocorre na margem de mata periodicamente inundada. Nas restingas do Rio de Janeiro, foi coletada em flor e fruto em fevereiro e abril.

\section{Oxandra A. Rich.}

Árvores ou arbustos. Tricomas simples. Flor 1 ou em inflorescência, axilar, monoclinas; sépalas três, conatas na base; pétalas seis, livres, imbricadas; estames poucos, conectivo dilatado no ápice, esse lanceolado, anteras não septadas transversalmente, estaminódios ausentes; carpelos poucos, óvulo um, basal. Fruto apocárpico, carpídios curtamente estipitados ou sésseis, indeiscentes; semente uma, sem arilo.

Oxandra possui cerca de 22 espécies distribuídas do Panamá ao sul do Brasil (Kessler 1993). 
7. Oxandra nitida R.E.Fr., Acta Horti Berg. 10(2): 160. f. 4c. 1931.

Figura $1 \mathrm{k}$.

Árvores, 5-10 m alt. Pecíolo 3-5 mm compr., marrom. Lâminas foliares 5-10 x 2$4,5 \mathrm{~cm}$, cartáceas a subcoriáceas, elípticas a estreitamente obovadas, verdes discolores, brilhantes na face adaxial; base aguda; ápice agudo; nervura primária plana a proeminente na face adaxial, proeminente na abaxial. Flores em inflorescência, axilar; botão ca. $2 \times 4 \mathrm{~mm}$, elipsóide; pedicelo ca. $5 \mathrm{~mm}$ compr.; brácteas muitas; flores maduras não vistas. Fruto apocárpico; carpídios 10-15 x 8-12 mm, ovóides, sésseis.

Material analisado: Saquarema: Reserva Ecológica Estadual de Jacarepiá, 22 ${ }^{\circ} 55^{\prime} \mathrm{S}$ 42²6'W, elev. 10-15 m, 22.II.1999, bot., P. J. Maas et al. 8839 (RB), id., P. J. Maas et al. 8840 (RB).

Oxandra nitida pode ser reconhecida por suas folhas elípticas a estreitamente obovadas, brilhantes na face adaxial (Maas et al. 2002) e pela nervura primária plana a proeminente na face adaxial. É encontrada na Bahia, Espírito Santo e Rio de Janeiro (Maas et al. 2002), na floresta pluvial dos tabuleiros, floresta pluvial atlântica de baixada e baixomontana e restinga. Nas restingas do Rio de Janeiro, ocorre nas florestas sobre cordão. Foi coletada em botão em fevereiro.

\section{Xylopia L.}

Árvores ou arbustos. Tricomas simples. Flores em inflorescência, axilares ou caulinares, monoclinas; botão estreitamente piramidal; sépalas três, conatas na base, valvares, raramente imbricadas; pétalas seis, livres, valvares, as internas menores; estames numerosos, anteras septadas transversalmente, ápice do conectivo dilatado, truncado, estaminódios presentes; carpelos poucos a muitos, óvulos 2-8. Fruto apocárpico, carpídios elipsóides, em geral estipitados, deiscentes ou indeiscentes; sementes 2-8, com arilo.

Xylopia é pantropical e possui entre 100160 espécies (Kessler 1993).
8. Xylopia ochrantha Mart., in Mart., Fl. bras. 13(1): 43. 1841.

Nome popular: Coração (Corrêa 1984).

Figura 1 1-m.

Arvoretas, 2,5-4 m alt. Pecíolo $6 \mathrm{~mm}$ compr., marrom. Lâminas foliares 6-10 x 2,5$4 \mathrm{~cm}$, cartáceas a subcoriáceas, elípticas, verdes discolores, glabras em ambas as faces, brilhantes na adaxial; base aguda; ápice acuminado, acúmem 5-10 mm compr.; nervura primária impressa na face adaxial, proeminente na abaxial. Flores em inflorescência, caulinares; botão $1-2 \times 1 \mathrm{~cm}$, piramidal; pedicelo 2-5 mm compr.; brácteas 1-4; sépalas e pétalas densamente cobertas por tricomas adpressos, ferrugíneos; sépalas 5-7 x 6-8 mm; pétalas do ciclo externo $17-20 \times 10 \mathrm{~mm}$, do interno ca. $15 \times 7 \mathrm{~mm}$; estames $1-2 \mathrm{~mm}$ compr.; carpelos muitos, ca. $3 \mathrm{~mm}$ compr. Fruto apocárpico; carpídios 15-40 x 6-10 mm, deiscentes, densamente cobertos por tricomas adpressos, ferrugíneos; sementes 4-7.

Material analisado: Macaé: fazenda Jurubatiba, 17.IX.1986, fr., D. Araujo et al. 7553 (RB); 8.VII.1994, fr., C. Farney et al. 3402 (RB). Rio de Janeiro: Restinga de Jacarepaguá, 17.VI.1958, fr., E. Pereira et al. 3841 (RB); ib., lado norte da pedra de Itaúna, 10.V.1969, fr., D. Sucre et al. 5023 (RB); estrada do Autódromo, a $150 \mathrm{~m}$ da Lagoa de Marapendi, 1972, fr., J. A. Jesus 1790 (RB); Lagoa de Marapendi, 10.XI.1972, fl., J. A. Jesus 2120 (RB); Barra da Tijuca, Av. das Américas, próximo aos Pontões, 28.II.1999, fl., H. C. Lima 5685 (RB).

Xylopia ochrantha é caracterizada pelas flores e frutos caulinares cobertos por tricomas ferrugíneos (Maas et al. 2002). Ocorre no Brasil, nos estados da Bahia, Espírito Santo e Rio de Janeiro (Maas et al. 2002; Fries 1930), em restinga. De acordo com o material depositado no herbário do RB, a espécie também ocorre no Pará, serra dos Carajás, na floresta pluvial amazônica. Nas restingas fluminenses, ocorre nas formações arbustivas abertas (incluindo as formações de Clusia do Parque Nacional da Restinga de 
Jurubatiba) e nas florestas sobre cordão (mata seca). É freqüente nas formações arbustivoarbóreas que margeiam as lagoas desse PARNA (obs. pess.). Nas restingas do Rio de Janeiro, foi coletada em flor em janeiro, fevereiro, maio, junho e de setembro a dezembro e em fruto de maio a julho e setembro.

9. Xylopia sericea A. St.-Hil., F1. Bras. merid. 1(2): 41.1825.

Figura 1 n-p.

Nomes populares: pindaíba vermelha, pimenta do mato, pau de anzol, pau de embira (Corrêa 1984), pimenta de macaco, entre outros.

Árvore, ca. $8 \mathrm{~m}$ alt. Pecíolo ca. $5 \mathrm{~mm}$ compr., marrom. Lâminas foliares 7-10,5 x 1$2 \mathrm{~cm}$, subcoriáceas, estreitamente elípticas, verdes discolores, glabras na face adaxial, densamente cobertas por tricomas adpressos na abaxial; base aguda; ápice agudo; nervura primária impressa na face adaxial, proeminente na abaxial. Flores em inflorescência, axilares; botão ca. 7 x $18 \mathrm{~mm}$, elipsóide; pedicelo 1-2 mm compr.; brácteas muitas; sépalas e pétalas densamente cobertas por tricomas adpressos, ferrugíneos; sépalas ca. 3 x $3 \mathrm{~mm}$; pétalas do ciclo externo ca. $10 \times 2 \mathrm{~mm}$, do interno ca. 8 x $1 \mathrm{~mm}$; estames ca. $1 \mathrm{~mm}$ compr., carpelos poucos, ca. $2 \mathrm{~mm}$ compr. Fruto apocárpico; carpídios 12-20 × 8-10 mm, deiscentes, densamente cobertos por tricomas adpressos, ferrugíneos; sementes 2-4.

Material analisado: Araruama: estrada Sobradinho-São Vicente de Paula, 9.X.2002, fl., C. Farney 4493 (RB).

Material analisado adicional: RIO DE JANEIRO: Magé: ca. $3 \mathrm{~km}$ SE de Santo Aleixo, 22 $35^{\circ}$ 'S $43^{\circ} 2^{\prime} \mathrm{W}$, elev. menos de $50 \mathrm{~m}$, 3.VI.1985, fr., R. Guedes 946 (RB).

Xylopia sericea fornece madeira própria para mastros de pequenas embarcações. As fibras da casca são usadas na indústria caseira de cordoaria. As sementes substituem a pimenta do reino ou a da índia como condimento. É árvore ornamental (Corrêa 1984). Ocorre na
América do Sul, da Venezuela e Guiana até a Bolívia (www.mobot.org - 4/7/2005), e no Brasil, nos estados de Roraima, Bahia, Goiás, Minas Gerais, Rio de Janeiro (Fries 1930) e, de acordo com o material depositado no herbário RB, Mato Grosso, Distrito Federal e Espírito Santo. Apresenta-se distribuída numa grande variedade de habitats, como: cerrado, floresta pluvial ripária, campo rupestre, floresta pluvial dos tabuleiros, floresta pluvial atlântica de baixada e montana, restinga, floresta estacional e vegetação alterada (Kurtz 2001). No Parque Nacional da Restinga de Jurubatiba, ocorre na borda e interior das florestas periodicamente inundadas, podendo alcançar $18 \mathrm{~m}$ de altura (obs. pess.). Nas restingas do Rio de Janeiro, foi coletada em flor em outubro e em fruto em janeiro e março.

Das nove espécies aqui tratadas, Annona acutiflora, que prefere os ambientes abertos, é a mais frequiente, sendo encontrada em praticamente todas as restingas fluminenses, da Marambaia até o Parque Nacional da Restinga de Jurubatiba. Três espécies são citadas pela primeira vez para as restingas do estado: Annona montana, Anaxagorea dolichocarpa e Guatteria nigrescens. As duas últimas, junto com Duguetia sessilis e Oxandra nítida, são típicas das matas de restinga.

\section{REFERÊNCIAS B IBLIOG RÁFICAS}

APG - Angiosperm Phylogeny Group. 2003. An update of the Angiosperm Phylogeny Group classification for the orders and families of flowering plants: APG II. Botanical Journal of the Linnean Society 141: 399-436.

Araujo, D. S. D. 1992. Vegetation types of sandy coastal plains of tropical Brazil: a first approximation. In: Seeliger, U. (ed.). Coastal Plant Communities of Latin America. New York, Academic Press, p. 337-347.

Araujo, D. S. D. \& Maciel, N. C. 1998. Restingas fluminensis: biodiversidade e preservação. Boletim FBCN 25: 27-51.

Rodriguésia 56 (87): 85-96. 2005 
Araujo, D. S. D.; Scarano, F. R.; Sá, C. F. C.; Kurtz, B. C.; Zaluar, H. L. T.; Montezuma, R. C. M. \& Oliveira, R. C. 1998. As comunidades vegetais do Parque Nacional da Restinga de Jurubatiba. In: Esteves, F. A. (ed.). Ecologia das lagoas costeiras do Parque Nacional da Restinga de Jurubatiba e do município de Macaé (RJ). UFRJ, Rio de Janeiro: 39-62.

Chatrou, L. W.; Rainer, H. \& Maas, P. J. M. 2004. Annonaceae (Soursop Family). In: Smith, N. et al. (eds.). Flowering Plants of the Neotropics. New York Botanical Garden, New York, p. 18-20.

Corrêa, M. P. 1984. Dicionário das plantas úteis do Brasil e das exóticas cultivadas. Imprensa Nacional, 6: 777.

Fonseca-Kruel, V. S. \& Peixoto, A. L. 2004. Etnobotânica na Reserva Extrativista Marinha de Arraial do Cabo, Rio de Janeiro, Brasil. Acta Botanica Brasilica 18(1): 177-190.

Fonseca, V. S. 1998. Etnobotânica da Reserva Ecológica Estadual de Jacarepiá, Saquaremal RJ: Um ensaio. Rio de Janeiro, Monografia de Bacharelado, Instituto de Ciências Biológicas e Ambientais, USU, 97p.

Fries, R. E. 1930. Revision der Arten einiger Anonaceen-Gattungen. I. Acta Horti Bergiani 10(1): 1-128.

1931. Revision der Arten einiger Anonaceen-Gattungen. II. Acta Horti Bergiani 10(2): 129-341.

Kessler, P. J. A. 1993. Annonaceae. In: Kubitski, K., Rohwer, J. C. \& Bittrich, V. (eds.). The families and genera of vascular plants II: Flowering plants. Dicotyledons. Magnoliid, Hamamelid and Caryophyllid families. Springer-Verlag, Berlin, 93-129.

Kurtz, B. C. 2001. Annonaceae. In: Costa, A. F. \& Dias, I. C. A. (org.). Flora do Parque Nacional da Restinga de Jurubatiba e arredores, Rio de Janeiro, Brasil: listagem, florística e fitogeografia. Angiospermas, pteridófitas, algas continentais. Museu Nacional, Rio de Janeiro, RJ, 26-27.
Lobão, A. Q. 2003. Guatteria (Annonaceae) do Estado do Rio de Janeiro. Dissertação. Universidade de São Paulo. São Paulo.

Maas, P. J. M.; Kamer, H. M.; Junikka, L.; Mello-Silva, R. \& Rainer, H. 2002 (2001). Annonaceae of eastern and south-eastern Brazil (Bahia, Espírito Santo, Goiás, Minas Gerais, Mato Grosso, São Paulo \& Rio de Janeiro). Rodriguésia 52(80): 61-94.

Maas, P. J. M.; Mennega, E. A. \& Westra, L. Y. 1994. Studies in Annonaceae XXI. Index to species and infraspecific taxa of Neotropical Annonaceae. Candollea 49(2): 389-481.

Maas, P. J. M. \& Westra, L. Y. 1984-1985. Studies in Annonaceae. II. A monograph of the genus Anaxagorea A.St.-Hil. Part 2. Botanische Jahrbücher für Systematik 105(2): 145-204.

Maas, P. J. M. \& Westra, L. Y. 2003. Duguetia (Annonaceae). Flora Neotropica 88: 1-276.

Maas, P. J. M.; Westra, L. Y. ; Meijdam, N. A. J. \& Tol, I. A. V. 1993. Studies in Annonaceae XV. A taxonomic revision of Duguetia A.St-Hil. sect. Geanthemum (R.E.Fr.) R.E.Fr. (Annonaceae). Bolletim Museu Paraense Emílio Goeldi, série Botânica 9(1): 31-58.

Mello-Silva, R. 1992. Annonaceae. In: Fiuza Melo, M. M. R. et al. (eds.). Flora fanerogâmica da Ilha do Cardoso, São Paulo, Brasil. Instituto de Botânica, São Paulo 3: 43-51.

Pontes, A.; Barbosa, M. R. V. \& Maas, P. J. M. 2004. Flora Paraibana: Annonaceae Juss. Acta Botanica Brasilica 18(2): 281293.

Radford, A. E.; Dickison, W. C.; Massey, J. R. \& Bell, C. R. 1974. Vascular plant systematic. Harper \& Row Publ., New York, 891p.

Scarano, F.R. 2002. Structure, function and floristic relationships of plant communities in stressful habitats marginal to the Brazilian Atlantic rainforest. Annals of Botany 90: 517-524. 
Steyermark, J.; Berry, P. \& Holst, B. 1995. Annonaceae. In: Berry, P. E.; Holst, B. K. \& Yatskievych, K. (eds.). Flora of the Venezuelan Guayana. Timber Press, Portland, 2: 413-462. 
